\title{
Analgesic efficacy of dexmedetomidine used for epidural anesthesia on labor analgesia.
}

\author{
Wang Jun ${ }^{1}$, An Zhengzhuang ${ }^{2}$, Ou Li ${ }^{*}$ \\ ${ }^{1}$ The Second Affiliated Hospital of Shaanxi University of Chinese Medicine, Shaanxi Province, PR China \\ ${ }^{2}$ Affiliated Hospital of Shaanxi University of Chinese Medicine, PR China
}

\begin{abstract}
Objective:Toinvestigatetheanalgesic effect of dexmedetomidine in epidural anesthesia for labor analgesia.

Methods: 150 nulliparous patients were randomly divided into two groups with 75 cases each: ropivacaine group $(R)$ and ropivacaine+dexmedetomidinegroup $(R+Y)$. $R$ group received analgesia with $0.1 \%$ ropivacaine and $\mathrm{R}+\mathrm{Y}$ group received $0.1 \%$ ropivacaine and $0.5 \mu \mathrm{g} / \mathrm{ml}$ dexmedetomidine. The background infusion $10 \mathrm{ml} / \mathrm{h}$, bonus $5 \mathrm{ml}$, lockout time $20 \mathrm{~min}$. Vital signs, VAS of pain, progress of labor, neonatal Apgar score, postpartum haemorrhage amount, side effects and serum level of IL-6 and TNF- $\alpha$ were recorded.

Results: Heart rate and mean arterial pressure of two groups were decreased after analgesia, but still in the normal range. The total stage of labor of $R$ group was $(608.2 \pm 98.4 \mathrm{~min})$ longer than the $R+Y$ group. Two groups of total labor have a significant difference, especially in the first and second labor. The VAS score of the two groups all decreased after analgesia, score of $R+Y$ group was lower than the other. There were no significant differences in the side effects, postpartum haemorrhage amount and neonatal Apgar score between the two groups. The serum level of IL-6 and TNF- $\alpha$ in $R+Y$ group were lower than the $R$ group in childbirth and $24 \mathrm{~h}$ after it.

Conclusion: Dexmedetomidine used for epidural anesthesia on labor analgesia has high effect and safety. It can promote the progress of labor without severe side effects. Combination of ropivacaine +dexmedetomidine is better medicine mode for labor analgesia.
\end{abstract}

Keywords: Labor analgesia, Dexmedetomidine, Ropivacaine, Epidural anesthesia.

Accepted on November 2, 2017

\section{Introduction}

Labor pain often causes a strong stress response in women and increases the risk of childbirth. Meanwhile, to some extent increases the rate of cesarean section. Thus in recent years, it is concerned by most mothers and doctors that how to effectively alleviate the pain in childbirth. Labor analgesia, also known as painless childbirth, refers to the use of various methods to reduce maternal labor pain or make it disappear. The ideal labor analgesia should be based on maternal and child safety, and should have fast acting, good analgesic effect and less adverse reaction. At present, epidural block anesthesia is convenient, and has less adverse reaction and obvious effect in the commonly used analgesic methods, which is widely used in the current way of analgesia [1,2]. However, the selection of more effective and safer narcotic drugs remains to be discussed. Dexmedetomidine is a highly selective $\alpha 2$ adrenergic receptor agonist that has sedative, hypnotic, and analgesic effects. The purpose of this study is to investigate the effect of dexmedetomidine used as epidural analgesia on the curative effect of labor analgesia, and to provide a reference for clinical application.

\section{Materials and Methods}

\section{General information}

Ethical approval was given by the medical ethics committee of The Second Affiliated Hospital of Shaanxi University of Chinese Medicine with the following reference number: 2014016. This study has been approved by the medical ethics committee of our hospital and the informed consent has been signed. From January 2015 to December 2016, 150 cases of Ipara who voluntarily asked for labor analgesia were randomly divided into 2 groups: ropivacaine group (group L) and ropivacaine combined with right pyrimidine group (group L $+Y$ ) with 75 cases in each group. 


\section{Inclusion criteria}

Selection criteria: Age of 20-35 y, grades I and II according to the American Society of Anesthesiologists (ASA) classification, full-term singleton I-para (37-42 w of gestation), head position, normal fetal development, normal birth canal and no indication of broken uterus and all patients accepted the epidural nerve block voluntarily and signed the informed consent form. Exclude the following: contraindication of spinal anesthesia, hypersensitivity of narcotic drugs, fetus associated with obstetric complications, bradycardia, and associated with cephalopelvic disproportion, fetal distress, amniotic fluid and yeast infection. The clinical data of two groups of mothers are shown in Table 1. Ropivacaine group: average age $(26.5 \pm 4.6$ y old), average gestational age $(36.9 \pm 2.2 \mathrm{w})$, average weight $(62.8 \pm 4.6 \mathrm{~kg})$, average height $(165.5 \pm 5.5 \mathrm{~cm})$. Ropivacaine combined with right pyrimidine group: average age $(25.5 \pm 3.5$ y old), average gestational age $(37.6 \pm 1.2 \mathrm{w})$, average weight $(61.4 \pm 5.6 \mathrm{~kg})$, average height $(166.2 \pm 3.5 \mathrm{~cm})$. There was no significant difference between the two groups in the general data such as age, gestational age, weight, height, and so on, and $\mathrm{P}>0.05$, which were comparable.

Table 1. Comparison of general data of two groups of parturients.

\begin{tabular}{|c|c|c|c|c|c|}
\hline Group & $\mathrm{n}$ & $\begin{array}{l}\text { Age (years } \\
\text { old) }\end{array}$ & $\begin{array}{l}\text { Gestational } \\
\text { age (week) }\end{array}$ & Weight (kg) & Height $(\mathrm{cm})$ \\
\hline $\mathrm{R}$ group & 75 & $26.5 \pm 4.6$ & $36.9 \pm 2.2$ & $62.8 \pm 4.6$ & $165.5 \pm 5.5$ \\
\hline$R+Y$ group & 75 & $25.5 \pm 3.5$ & $37.6 \pm 1.2$ & $61.4 \pm 5.6$ & $166.2 \pm 3.5$ \\
\hline$P$ & - & $P>0.05$ & $P>0.05$ & $P>0.05$ & $P>0.05$ \\
\hline
\end{tabular}

\section{Anesthesia method}

All parturients were routinely monitored for blood pressure, pulse and breathing, and fetal heart. During an incubation period of the first stage of labor, when regular uterine contraction appeared and mouth of womb opened about $3 \mathrm{~cm}$, anesthesia was started. Lateral horizontal of parturients was taken and the epidural puncture was performed with a combined trocar by an anaesthetist. The puncture site was L3-4 intercostal. After the puncture, the a tube was placed at head end for $3-4 \mathrm{~cm}$, then catheter was fixed and $1.0 \%$ lidocaine 3 $\mathrm{ml}$ was injected into the epidural space and observed for $5 \mathrm{~min}$. If no subarachnoid block and local anesthetic toxicity reaction appeared, an epidural analgesia pump was followed. Group L:
$0.1 \%$ ropivacaine; group $\mathrm{L}+\mathrm{Y}: 0.1 \%$ ropivacaine, $+0.5 \mu \mathrm{g} / \mathrm{ml}$ dexmedetomidine mixture. Setting: first dose $10 \mathrm{ml}$, background infusion $10 \mathrm{ml} / \mathrm{h}$, a single additional quantity $5 \mathrm{ml}$, and lock time for $20 \mathrm{~min}$.

\section{Observation index}

1. Records of the vital signs of the parturients: the heart rate, mean arterial pressure, and oxygen saturation at $30 \mathrm{~min}$ before anesthesia and after anesthesia; 2. records of two groups duration of labor: active phase of labor at the first stage, the second stage, the third stage; 3. satisfaction of analgesia: Visual Analogue Scale (VAS score) was adopted: before analgesia (T1), $30 \mathrm{~min}$ after the onset of analgesia (T2) and during delivery (T3), the total score was 10 points, and the high scores indicated the pain was heavy; 4. neonatus condition: after apgar score 5 min after the birth; 5 . the amount of postpartum hemorrhage; 6. the adverse reactions: skin itching, nausea, vomiting, bradycardia, hypotension, etc.; 7. the change of inflammatory factors: peripheral blood IL-6 and TNF- $-\alpha$ of parturients before analgesia, at birth, $24 \mathrm{~h}$ after delivery were determined.

\section{Statistical methods}

Statistical analysis was performed by SPSS 19.0 software, and the measurement data were expressed by $\overline{\mathrm{x}} \pm \mathrm{s}$, random design data, one-way ANOVA was used for statistical analysis of group data, chi square $\left(\chi^{2}\right)$ test was used for count data, and $\mathrm{P}<0.05$ indicated the difference was statistically significant.

\section{Result}

\section{Comparison of vital signs before and after anesthesia in two groups of parturients}

Before anesthesia, there was no significant difference in heart rate, mean arterial pressure and blood oxygen saturation between the two groups $(\mathrm{P}>0.05)$. Compared with those before anesthesia, maternal heart rate, mean arterial pressure of the two groups $30 \mathrm{~min}$ after anesthesia decreased and the values were within the normal range with statistically significant difference $(\mathrm{P}<0.05)$. There was no significant difference in blood oxygen saturation between the two groups' parturients $30 \mathrm{~min}$ after anesthesia, compared with those before anesthesia $(\mathrm{P}>0.05)$, as shown in Table 2 .

Table 2. Comparison of vital signs in the two groups before and after anesthesia $(\bar{x} \pm s)$. Compared with that before anesthesia, ${ }^{*} P<0.05$; compared with that before anesthesia, ${ }^{\#} P>0.05$.

\begin{tabular}{|c|c|c|c|c|c|c|c|}
\hline \multirow[t]{2}{*}{ Group } & \multirow[t]{2}{*}{$\mathbf{n}$} & \multicolumn{2}{|c|}{ Heart rate (beats per min) } & \multicolumn{2}{|l|}{ MABP (mmHg) } & \multicolumn{2}{|c|}{ Blood oxygen saturation (\%) } \\
\hline & & Preanesthesia & Postanesthetic & Preanesthesia & Postanesthetic & Preanesthesia & Postanesthetic \\
\hline $\mathrm{R}$ group & 75 & $90.2 \pm 8.4$ & $80.1 \pm 4.4^{*}$ & $93.2 \pm 9.8$ & $82.1 \pm 9.5^{*}$ & $98.2 \pm 0.5$ & $98.5 \pm 0.4^{\#}$ \\
\hline$R+Y$ group & 75 & $89.1 \pm 5.6$ & $78.3 \pm 3.1^{*}$ & $94.8 \pm 9.7$ & $83.3 \pm 7.5^{*}$ & $98.2 \pm 0.3$ & $98.4 \pm 0.4^{\#}$ \\
\hline
\end{tabular}




\section{Comparison of duration of labor women in the two groups}

The total stage of labor for ropivacaine group was (608.2 \pm $98.4 \mathrm{~min})$, the total stage of labor for ropivacaine combined with dexmedetomidine was $(530.4 \pm 87.4 \mathrm{~min})$, and there was significant difference between the two groups in total stage of labor, $\mathrm{P}<0.05$. The duration of the first expulsive stage and the second expulsive stage in ropivacaine combined with dexmedetomidine group were less than those in ropivacaine group, the difference of which was statistically significant, $\mathrm{P}<0.05$, as shown in Table 3 .

Table 3. Comparison of parturients' duration of labor in the two groups $(\bar{x} \pm s)$.

\begin{tabular}{|c|c|c|c|c|c|}
\hline Group & $\mathbf{n}$ & $\begin{array}{l}\text { First } \\
\text { expulsive } \\
\text { stage (min) }\end{array}$ & $\begin{array}{l}\text { Second } \\
\text { expulsive } \\
\text { stage (min) }\end{array}$ & $\begin{array}{l}\text { Third } \\
\text { expulsive } \\
\text { stage (min) }\end{array}$ & $\begin{array}{ll}\text { Total stage } \\
\text { of } & \text { labor } \\
(\mathrm{min}) & \end{array}$ \\
\hline $\mathrm{R}$ group & 75 & $533.3 \pm 80.1$ & $48.1 \pm 10.1$ & $12.2 \pm 2.1$ & $608.2 \pm 98.4$ \\
\hline$R+Y$ group & 75 & $480.4 \pm 65.2$ & $36.8 \pm 11.5$ & $11.8 \pm 2.4$ & $530.4 \pm 87.4$ \\
\hline$P$ & - & $<0.05$ & $<0.05$ & $>0.05$ & $<0.05$ \\
\hline
\end{tabular}

\section{Comparison of VAS scores in the two groups of parturients at each time point}

There was no significant difference in the VAS score between the two groups of parturients before anesthesia $(\mathrm{P}>0.05)$. At the two time points such as after the onset of analgesia (T2) and during delivery (T3), VAS scores were lower than those of $\mathrm{T} 1$ in intra group comparison. Among them, the VAS score of parturients in ropivacaine combined with dexmedetomidine group were lower than those in ropivacaine group, $\mathrm{P}<0.05$, and the difference was statistically significant, as seen in Table 4.

Table 4. Comparison of VAS scores in two group of parturients at each time point $(\bar{x} \pm s)$. Intra group comparison, compared with T1, ${ }^{*} P<0.05$; comparisons between groups, ${ }^{\#} P<0.05$.

\begin{tabular}{lllll}
\hline Group & $\mathbf{n}$ & $\mathbf{T 1}$ & $\mathbf{T 2}$ & T3 \\
\hline R group & 75 & $8.3 \pm 0.6$ & $3.7 \pm 0.5^{*}$ & $1.2 \pm 0.5^{*}$ \\
\hline $\mathrm{R}+\mathrm{Y}$ group & 75 & $8.4 \pm 0.6$ & $2.2 \pm 0.2^{* \#}$ & $0.7 \pm 0.3^{* \#}$ \\
\hline
\end{tabular}

Neonatal score and postpartum hemorrhage amount apgar scores of the two groups $5 \mathrm{~min}$ after birth were respectively $(9.4 \pm 0.3),(9.4 \pm 0.4)$, and there was no significant difference between the two groups, $\mathrm{P}>0.05$. The average postpartum bleeding volume of $\mathrm{R}$ group was $(170.6 \pm 37.5 \mathrm{ml})$, the average postpartum bleeding volume of $\mathrm{R}+\mathrm{Y}$ group was $(164.8 \pm 28.6$ $\mathrm{ml})$, and the difference between the two groups was not statistically significant, $\mathrm{P}>0.05$, as shown in Table 5 .

Table 5. Neonatal score and postpartum hemorrhage amount.

\begin{tabular}{llll}
\hline Group & $\mathbf{n}$ & $\begin{array}{l}\text { Apgar scores } \\
\text { after birth }\end{array}$ & $\mathbf{5}$ min $\begin{array}{l}\text { Postpartum } \\
\text { hemorrhage amount }\end{array}$ \\
\hline R group & 75 & $9.4 \pm 0.3$ & $170.6 \pm 37.5$ \\
\hline
\end{tabular}

\begin{tabular}{llll}
\hline $\mathrm{R}+\mathrm{Y}$ group & 75 & $9.4 \pm 0.4$ & $164.8 \pm 28.6$ \\
\hline $\mathrm{P}$ & - & $>0.05$ & $>0.05$ \\
\hline
\end{tabular}

\section{Comparison of adverse reactions incidence in two groups of parturients}

In group L, there were 5 cases of nausea and vomiting, 2 cases of urinary retention, and 1 case of itch of skin. There was no significant difference in the incidence of adverse reactions between the two groups, $\mathrm{P}>0.05$ (Table 6).

Table 6. Comparison of adverse reactions incidence in two groups of parturients.

\begin{tabular}{lllllll}
\hline Group & $\mathbf{n}$ & $\begin{array}{l}\text { Nausea and } \\
\text { vomiting }\end{array}$ & $\begin{array}{l}\text { Urinary } \\
\text { retentio } \\
\mathbf{n}\end{array}$ & $\begin{array}{l}\text { Itch } \\
\text { skin }\end{array}$ & $\begin{array}{l}\text { Bradycardi } \\
\mathbf{a}\end{array}$ & $\begin{array}{l}\text { Incidence } \\
\text { of adverse } \\
\text { reactions }\end{array}$ \\
\hline R group & 75 & 5 & 2 & 1 & 0 & $10.7 \%$ \\
\hline $\begin{array}{l}\mathrm{R}+\mathrm{Y} \\
\text { group }\end{array}$ & 75 & 3 & 1 & 2 & 0 & $8.0 \%$ \\
\hline $\mathrm{P}$ & - & $>0.05$ & $>0.05$ & $>0.05$ & - & $>0.05$ \\
\hline
\end{tabular}

\section{Changes of serum inflammatory factors before and after anesthesia in two groups of parturients}

There was no significant difference in serum IL-6 and TNF- $\alpha$ levels between the two groups of parturients before anesthesia, $\mathrm{P}>0.05$. In group $\mathrm{L}$ and group $\mathrm{L}+\mathrm{Y}$, the levels of IL- 6 and TNF- $\alpha$ during laboring were higher than those before anesthesia. But in group $\mathrm{L}$ at delivery and $24 \mathrm{~h}$ after parturition, IL-6 and TNF- $\alpha$ were higher than those before anesthesia and significantly higher than those of group $\mathrm{L}+\mathrm{Y}$, the difference of which was statistically significant, $\mathrm{P}<0.05$, as shown in Table 7.

Table 7. Changes of serum inflammatory factors before and after anesthesia in two groups of parturients. Intra group comparison: compared with pre anesthesia, ${ }^{*} P<0.05$; comparison between groups: compared with group $L$ at the same time, ${ }^{\#} P<0.05$.

\begin{tabular}{llll}
\hline Group & Time point & IL-6 $(\mathrm{pg} / \mathrm{m} \mathrm{L})$ & TNF- $\alpha(\mathbf{f m o l} / \mathrm{ml})$ \\
\hline R group & Preanesthesia & $79.5 \pm 1.0$ & $7.2 \pm 0.7$ \\
\cline { 2 - 4 } & At delivery & $115.5 \pm 3.5^{*}$ & $8.1 \pm 1.3^{*}$ \\
\cline { 2 - 4 } & 24 h after delivery & $120.6 \pm 2.9^{*}$ & $8.3 \pm 0.6^{*}$ \\
\hline R+Y group & Preanesthesia & $78.6 \pm 1.2$ & $7.2 \pm 0.8$ \\
\cline { 2 - 4 } & At delivery & $106.3 \pm 1.5^{* \#}$ & $7.4 \pm 0.8^{* \#}$ \\
\cline { 2 - 4 } & 24 h after delivery & $108.5 \pm 3.0^{* \#}$ & $8.0 \pm 0.5^{* \#}$ \\
\hline
\end{tabular}

\section{Discussion}

Because of the obvious effect, and less adverse reactions of epidural nerve block anesthesia, at present, it is widely used in clinical labor analgesia. The clinical use of a small amount of narcotic drugs makes parturients deliver in painless or less painful state. And because the drug does not block the motor 
nerves of the uterus, it ensures that the parturient has normal uterine contraction ability $[3,4]$. At present, most domestic and foreign clinical use of ropivacaine as regional nerve block labor analgesia method can achieve better painless childbirth requirements. To optimize the combination of anesthetics, through the study on the effect of epidural dexmedetomidine on the curative effect of labor analgesia, this study investigated the analgesic efficacy and safety of dexmedetomidine to definite the optimal and best way to ease pain.

Through the function in adrenergic receptor $\alpha 2$ in nucleus coeruleus of brain stem, Dexmedetomidine [5,6] can produce sedation, hypnosis, and anxiolytic effects. It is a potent, highly selective $\alpha 2$ adrenergic receptor agonists with receptor selectivity $\alpha 2$ : $1=1620: 1$, which has not only sedative and anxiolytic effects, but also analgesic and sympathetic nerve block effects [7]. In recent years, dexmedetomidine [8] has been used more and more in clinical anesthesia, and it can reduce the occurrence of stress reaction during operation, improve the recovery process of anesthesia as well as reduce the dosage of other narcotic drugs. This study found that the VAS scores of parturients in ropivacaine combined with dexmedetomidine group was lower than those in ropivacaine group and the analgesic effect of parturients in ropivacaine combined with dexmedetomidine group was better than that of ropivacaine alone group. In addition, dexmedetomidine can enhance uterine contraction and frequency [9]. In this study, total stage of labor of the ropivacaine group was $(608.2 \pm 98.4$ min), total stage of labor of ropivacaine combined with dexmedetomidine group was (530.4 $\pm 87.4 \mathrm{~min})$, and there was significant difference between the two groups in total stage of labor. Among them, the duration of the first and third stages of labor in ropivacaine combined with dexmedetomidine group was shorter than that of the ropivacaine group. Dexmedetomidine is beneficial to speed up the labor process, and help women relax, save energy, as well as avoid or reduce the amount of oxytocin [10,11]. It can be seen that dexmedetomidine group can effectively improve the analgesic effect of epidural nerve block during painless labor and promote the progress of labor.

Dexmedetomidine can produce a kind of sedation which is similar to natural sleep, and patients can be awakened by external stimulation and coordinate with the instruction, which can make parturients consciously participate in the delivery process. And in the whole process, dexmedetomidine does not have obvious function of inhibiting respiration [12-14]. The major potential toxic effect of dexmedetomidine is bradycardia $[15,16]$, however, no significant decrease of heart rate during analgesia was observed in this study. The results showed that the heart rate, mean arterial pressure in the two groups of parturients $30 \mathrm{~min}$ after anesthesia were decreased compared with those before anesthesia, but the value was still within normal range. At the same time, the incidence of adverse reaction in the two groups were not statistically significant, suggesting that dexmedetomidine was equally safe for epidural analgesia through epidural nerve block and did not increase the incidence of adverse reactions. In the Apgar score, there was no significant difference in Apgar scores the $5 \mathrm{~min}$ after the birth of a new-born between the ropivacaine and the dexmedetomidine group and the ropivacaine group. The amount of postpartum hemorrhage in ropivacaine combined with dexmedetomidine group was slightly less than that in ropivacaine group, but there was no significant difference between the two groups. It is indicated that the group with additional use of dexmedetomidine in the delivery will not lead to postpartum uterine atony and will not increase the amount of postpartum hemorrhage. Therefore, ropivacaine combined with dexmedetomidine for epidural anesthesia is a safe way of delivery.

Mood and pain during labor can cause anxiety and stress, affect the neuroendocrine system and the immune system, resulting in incident of inflammation reaction and immunosuppression [17-19]. IL-6 is the major cytokine that leads to postoperative immune damage, and TNF- $\alpha$ is an initiating factor when inflammation reaction generates, which can amplify the function of inflammatory reaction. In this study, IL-6 and TNF- $\alpha$ in ropivacaine combined with dexmedetomidine group was significantly lower than those of ropivacaine group. To some extent, it indicated that the group with combination of dexmedetomidine can effectively relieve the pain during delivery and relieve anxiety and nervousness, at the same time, it can also effectively reduce the inflammatory reaction and immune suppression caused by pain and stress.

In conclusion, dexmedetomidine for epidural anesthesia has the advantages of good analgesic effect and high safety, which can promote the progress in labor, but does not increase incidence of adverse reactions. Combined use of the two kinds of drugs such as ropivacaine and dexmedetomidine can effectively relieve the pain and discomfort of labor as well as improve the comfort and satisfaction of delivery, at the same time ensure that the mother and child do not have serious adverse effects, which is the better optimization of drugs for labor analgesia.

\section{References}

1. Parua S, Choudhury D, Nath MP. Giant haemangioma excision under cervical epidural anaesthesia: a viable alternative to general anaesthesia. J Clin Diagn Res 2016; 10: $1-2$.

2. Xu Q, Zhang H, Zhu YM. Effects of combined general/ epidural anesthesia on hemodynamics, respiratory function, and stress hormone levels in patients with ovarian neoplasm undergoing laparoscopy. Med Sci Monit 2016; 22: 4238-4246.

3. Ramos JA, Shettar SS, James CF. Neuraxial analgesia in a parturient with the Vacterl association undergoing labor and vaginal delivery. Rev Bras Anestesiol 2017; 7094: 30343-30349.

4. Nunes J, Nunes S, VeigaM. A prospective, randomized, blinded-endpoint, controlled study-continuous epidural infusion versus programmed intermittent epidural bolus in labor analgesia. Rev Bras Anestesiol 2016; 66: 439-444. 
5. Zhang Y, Xi H. Research progress on the application of dexmedetomidine in clinical anesthesia. Med Recapitul 2014; 20: 317-319.

6. Alhammad AM, Baghdady NA, Mullin RA. Evaluation of the impact of a prescribing guideline on the use of intraoperative dexmedetomidine at a tertiary academic medical center. Saudi Pharm J 2017; 25: 144-147.

7. Brixval CS, Thygesen LC, Axelsen SF. Effect of antenatal education in small classes versus standard auditoriumbased lectures on use of pain relief during labour and of obstetric interventions: results from the randomised newborn trial. BMJ Open 2016; 6: 010761.

8. Abdalla W, Ammar MA, Tharwat AI. Combination of dexmedetomidine and remifentanil for labor analgesia: a double-blinded, randomized, controlled study. Saudi J Anaesth 2015; 9: 433-438.

9. Yan J, Pang J. Sedative effect and safety of auxiliary dexmedetomidine intravenous injection for epidural nerve blockepidural nerve block in painless delivery. Bethune Med J 2016; 14: 728-729.

10. Gao Y. Application progress of dexmedetomidine in obstetric anesthesia. Cont Med Educ 2016; 30: 145-147.

11. Fengmin GE, Zhuo H, Liu X. Different doses of dexmedetomidine anesthesia for clinical application in continuous epidural. Harbin Med J 2014.

12. Tien M, Allen TK, Mauritz A. A retrospective comparison of programmed intermittent epidural bolus with continuous epidural infusion for maintenance of labor analgesia. Curr Med Res Opin 2016; 32: 1435-1440.

13. Samanta S, Jain K, Bhardwaj N. Maternal and foetal outcome after epidural labour analgesia in high-risk pregnancies. Indian J Anaesth 2016; 60: 115-120.

14. Kjos K, Ghashghaei R, Klisser K. Investigation of maternal, fetal, and uteroplacental hemodynamics in high risk pregnancies. Western Regional Meeting of the American-Federation for Medical Research 2013; 124.

15. Zhao X, Wang X, Xue R. The application of ropivacaine combined with dexmedetomidine in epidural labor analgesia. Shaanxi Med J 2014; 43: 737-739.

16. Zhao Y, Xin Y, Liu Y. Effect of epidural dexmedetomidine combined with ropivacaine in labor analgesia: a randomized double-blinded controlled study. Clin J Pain 2016; 33: 319 .

17. Lin Y, Li Q, Liu J. Comparison of continuous epidural infusion and programmed intermittent epidural bolus in labor analgesia. Ther Clin Risk Manag 2016; 12: 1107-1112.

18. Delgado C, Ciliberto C, Bollag L. Continuous epidural infusion versus programmed intermittent epidural bolus for labor analgesia: optimal configuration of parameters to reduce physician-administered top-ups. Curr Med Res Opin 2017; 1 .

19. Tien M, Allen TK, Mauritz A. A retrospective comparison of programmed intermittent epidural bolus with continuous epidural infusion for maintenance of labor analgesia. Curr Med Res Opin 2016; 32: 1435-1440.

\section{*Correspondence to}

Ou Li

The Second Affiliated Hospital of Shaanxi University of Chinese Medicine

Shaanxi Province

PR China 